\title{
Maintenance everolimus beyond progression in pancreatic NET to control insulinoma syndrome
}

\author{
Valeria Tovazzi ${ }^{1}$ - Vittorio D. Ferrari ${ }^{1}$ - Alfredo Berruti ${ }^{1}{ }^{1}$ \\ Received: 6 December 2020 / Accepted: 28 December 2020 / Published online: 13 January 2021 \\ (c) The Author(s), under exclusive licence to Springer Science+Business Media, LLC part of Springer Nature 2021
}

\section{Dear Editor,}

The management of advanced/metastatic malignant insulinoma is challenging, since the goal of therapies is the control of both the tumor growth and the associated syndrome. Due to its antineoplastic properties and hyperglycaemic effect, Everolimus represents a suitable drug in insulinoma patients. Importantly, the symptoms control induced by everolimus can last longer than tumor control, so a maintainance beyond disease progression should be considered.

In their interesting letter, Zandee et al. [1] provided another point of view with respect to our concept of prolonging everolimus administration in insulinoma patients despite disease progression, in order to maintain the control of the syndrome [2]. They have previously shown in this setting that Peptide Receptor Radionuclide Therapy (PRRT), with agents like 177Lu-DOTATATE, can lead to major shrinkage and hypoglycaemic improvement [3]. Based on their consolidated experience they recommended switching to PRRT instead of continuing everolimus after clinical and radiological progression in insulinoma. It should be noted, however, that in their published insulinoma series, Zandee et al. [3] reported that seven out of nine patients with symptomatic disease needed to be admitted in hospital for extended clinical observation after PRRT administration due to management and prevention of hypoglycaemic crises. Three patients were treated with glucose infusion and four patients received octreotide subcutaneously. These findings suggest that PRRT is not immediately efficacious in insulinoma syndrome control. In addition, it is well known that somatostatin analogs can

Alfredo Berruti

alfredo.berruti@gmail.com

1 Department of Medical and Surgical Specialties, Radiological Sciences, and Public Health, Medical Oncology, University of Brescia at ASST Spedali Civili, Brescia, Italy increase but also reduce blood glucose concentrations in insulinoma patients, depending on the somatostatin receptor pattern of expression on neoplastic cells. Moreover, everolimus is usually given to patients with pancreatic NET progressing to somatostatin analogs, so the use of these drugs to control hypoglycaemia after everolimus discontinuation can not be applied. Therefore, our suggestion is that everolimus administration could be prolonged beyond progression in insulinoma patients in association with other therapies (including PRRT), to prevent possible hypoglycaemic crises. Obviously, the drug could be be withdrawn when a tumor shrinkage is obtained and/or the syndrome is completely controlled by the new therapy. This is what we did in our patient submitted to chemotherapy after everolimus progression. On the basis of these considerations we think that our point of view is not in contrast with the Zandee et al. position.

\section{Compliance with ethical standards}

Conflict of interest The authors declare that they have no conflict of interest

Publisher's note Springer Nature remains neutral with regard to jurisdictional claims in published maps and institutional affiliations.

\section{References}

1. W.T. Zandee, J. Hofland, W.W. de Herder, Should everolimus be stopped after radiological progression in metastatic insulinoma? A "pro" point of view. Endocrine (2021). https://doi.org/10.1007/ s12020-020-02570-4 [Online ahead of print]

2. V. Tovazzi, V.D. Ferrari, A. Dalla Volta, F. Consoli, V. Amoroso, A. Berruti, Should everolimus be stopped after radiological progression in metastatic insulinoma? A "cons" point of view. Endocrine 69(3), 481-484 (2020)

3. W.T. Zandee, B. Tessa, B. Anela, Symptomatic and radiological response to $177 \mathrm{Lu}-D O T A T A T E$ for the treatment of functioning pancreatic neuroendocrine tumors. J. Clin. Endocrinol. Metab. 104 (4), 1336-1344 (2019) 